\title{
Pengembangan modul komputasi fisika untuk mahasiswa jurusan kependidikan
}

\author{
Toni Kus Indratno \\ Program Studi Pendidikan Fisika, FKIP, Universitas Ahmad Dahlan \\ Jl. Kolektor Ringroad Selatan, Tamanan, Banguntapan, Bantul, D.I. Yogyakarta \\ Surat-e: tonikus@staff.uad.ac.id
}

Telah dilakukan pengembangan berupa modul petunjuk praktikum komputasi fisika yang ditujukan khusus untuk mahasiswa jurusan kependidikan. Modul ini hadir sebagai jawaban atas rumusan capaian pembelajaran yang dilakukan oleh Physical Society of Indonesia (PSI). Selain itu, modul ini juga sebagai bahan sumber belajar khususnya untuk mata kuliah komputasi fisika pada jurusan kependidikan. Modul ini dikembangkan berdasarkan hasil adaptasi model pengembangan Borg and Gall, Dick and Carey, serta Allessi and Trollip, hanya saja tahapan yang dilakukan hanya sampai tahap keenam. Hasil validasi oleh ahli materi menempatkan modul ini dalam kategori baik, sedangkan ahli media mengkategorikan nilai untuk modul ini sangat baik. Dalam rangka melihat respon pengguna, modul ini telah diujicobakan dengan skala terbatas kepada beberapa mahasiswa menggunakan instrumen USE Questionnaire. Pengguna menilai bahwa modul ini sangat baik dan layak untuk digunakan dalam perkuliahan komputasi fisika.

The development has been carried out consisting of modules on computational physics practicum intended specifically for students majoring in education. This module is present as an answer to the formulation of learning outcomes carried out by the Physical Society of Indonesia (PSI). In addition, this module is also a special learning resource for physics compatibility courses in the education department. This module was developed based on the adaptation model of Borg and Gall, Dick and Carey's development, and Allessi and Trollip, except that the development was carried out only until the sixth drunk. The results of the validation by the material expert put this module in a good category, while the media experts categorized the values for this module very well. In order to look at user responses, this module has been approved to try with a limited scale for some students using the USE Questionnaire instrument. Users consider this title very good and worthy of being used in computational physics lectures.

Kata kunci: modul komputasi fisika, modul praktikum

\section{Pendahuluan}

Komputasi fisika merupakan teknik penyelesaian persoalan-persoalan fisika secara numerik dengan bantuan komputer (Suparno, 2008). Penggunaan metode numerik teramat diperlukan khususnya untuk permasalahan yang tidak bisa diselesaikan secara analitik (Yanse, 2012). Secara umum ilmu komputasi adalah bidang ilmu yang mempunyai perhatian pada penyusunan model matematika dan teknik penyelesaian numerik serta penggunaan komputer untuk menganalisis dan memecahkan masalah-masalah ilmu (sains) (Mulyono \& Asih, 2013).

Dalam penggunaan praktis, biasanya berupa simulasi komputer atau berbagai bentuk komputasi lainnya untuk menyelesaikan masalah-masalah dalam berbagai bidang keilmuan, tetapi dalam perkembangannya digunakan juga untuk menemukan prinsip-prinsip baru yang mendasar dalam ilmu.

Dalam program studi jurusan kependidikan, seperti Prodi Pendidikan Fisika FKIP Universitas Ahmad Dahlan, Komputasi Fisika menjadi matakuliah wajib tempuh bagi mahasiswa semester 5 (Pendidikan Fisika, 2015). Asosiasi profesi, dalam hal ini adalah Himpunan Fisika Indonesia (HFI) telah menyusun Capaian Pembelajaran (CP) untuk tiap matakuliah, termasuk matakuliah Komputasi Fisika. Dalam dokumen CP yang telah disusun HFI, tertulis bahwa salah satu CP untuk sarjana pendidikan fisika adalah Menguasai matematika, komputasi, dan instrumentasi untuk mendukung pemahaman konsep fisika (ITS, 2014). Dalam CP ini dijabarkan bahwa mahasiswa diharapkan mempunyai kompetensi menguasai teknik komputasi dan 
instrumentasi untuk mendukung pemahaman konsep fisika (Tim, 2016). Dengan kompetensi ini, mahasiswa akan lebih menguasai konsep-konsep dasar fisika. Dalam tabel 1 berikut ditampilkan perbandingan CP mata kuliah Komputasi Fisika untuk mahasiswa jurusan kependidikan dan nonkependidikan.

Tabel 1. Perbandingan CP matakuliah Komputasi Fisika

\begin{tabular}{|c|c|c|}
\hline Matakuliah & $\begin{array}{c}\text { CP Jurusan } \\
\text { Kependidikan }\end{array}$ & $\begin{array}{c}\text { CP Jurusan } \\
\text { Nonkependidikan }\end{array}$ \\
\hline $\begin{array}{l}\text { Komputasi } \\
\text { Fisika }\end{array}$ & $\begin{array}{l}\text { Metode numerik } \\
\text { untuk } \\
\text { menyelesaikan } \\
\text { akar persamaan } \\
\text { polinomial, } \\
\text { persamaan linier, } \\
\text { dan persamaan } \\
\text { diferensial }\end{array}$ & $\begin{array}{l}\text { Metoda Numerik } \\
\text { penyelelesaian } \\
\text { difrensial/ turunan, } \\
\text { integral, berbagai } \\
\text { metoda penyelesaian } \\
\text { PD orde I, PD orde II, } \\
\text { PD dengan syarat } \\
\text { batas, Persamaan } \\
\text { difrensial parsial (PDP) } \\
\text { Elips, Parabolik dan } \\
\text { Hiperbolik }\end{array}$ \\
\hline
\end{tabular}

Dari tabel 1 diatas, nampak sekali perbedaan $\mathrm{CP}$ antara kedua jurusan. Namun, permasalahan yang muncul adalah belum tersedianya bahan ajar komputasi fisika yang khusus ditujukan untuk mahasiswa jurusan kependidikan. Bahan ajar tentang komputasi fisika memang telah banyak bertebaran di internet, namun sebagian besar merupakan bahan ajar untuk jurusan ilmu fisika maupun teknik fisika. Di mana kedua jurusan ini memiliki CP yang sedikit berbeda. Untuk jurusan-jurusan ilmu fisika murni, pembahasan komputasi fisika tentu lebih mendalam dengan metode-metode numerik yang lebih banyak. Sedangkan untuk jurusan kependidikan, pembahasan lebih pada dasar-dasar komputasi dengan metode umum yang mudah untuk dipahami.

Oleh karena itu, peneliti tertarik untuk mengembangkan bahan ajar berupa modul Komputasi Fisika yang khusus ditujukan untuk mahasiswa jurusan kependidikan. Modul dipilih karena dengan menggunakan bahan aar jenis ini, mahasiswa bisa belajar secara mandiri meski tanpa kehadiran dosen (Majid, 2012). Dalam modul juga berisi latihan-latihan yang bisa dikerjakan mahasiswa sehingga bisa lebih memahami dan menguasi konsep komputasi (Wulandari, 2016).

\section{Metode Penelitian}

Penelitian yang dilaksanakan ini merupakan jenis penelitian dan pengembangan atau Research and Development ( $\mathrm{R}$ and $\mathrm{D})$. Produk yang dikembangkan berupa modul praktikum komputasi fisika untuk mahasiswa jurusan kependidikan sebagai bagian dari perangkat pembelajaran praktikum komputasi fisika.

Model pengembangan yang yang digunakan dalam penelitian ini adalah jenis model pengembangan hasil adaptasi dari model Borg and Gall, Dick and Carey, serta Alessi and Trollip (Borg \& Gall, 1989) (Fitri, et al.,
2015). Langkah-langkah pengembangan secara umum terdiri atas sepuluh tahapan yaitu sebagai berikut:

1) Studi pendahuluan, analisis kebutuhan untuk mengumpulkan informasi (kajian pustaka, pengamatan kelas), identifikasi permasalahan yang dijumpai dalam pembelajaran, dan merangkum permasalahan;

2) Perencanaan atau menyusun rencana penelitian, meliputi: merumuskan tujuan pengembangan, desain atau langkah-langkah penelitian;

3) Pengembangan draf produk atau produk awal meliputi: penyiapan materi pembelajaran, dan penyusunan modul praktikum;

4) Uji coba lapangan tahap awal meliputi uji ahli materi dan ahli media (bahan pembelajaran);

5) Melakukan revisi terhadap produk uji coba, berdasarkan masukan dan saran-saran dari hasil uji lapangan awal.

6) Uji coba lapangan utama. Melakukan uji coba pada skala kecil atau sampel terbatas.

7) Melakukan revisi terhadap produk hasil uji coba lapangan utama.

8) Uji lapangan operasional, uji skala besar, data dikumpulkan melalui wawancara, observasi, dan kuesioner.

9) Penyempurnaan produk akhir, penyempurnaan didasarkan masukan dari uji pelaksanaan lapangan;

10) Mendiseminasikan dan mengimplementasikan produk, melaporkan dan menyebarluaskan produk melalui pertemuan dan jurnal ilmiah, bekerjasama dengan penerbit untuk sosialisasi produk untuk komersial, dan memantau distribusi dan kontrol kualitas.

Penelitian tahap pertama ini difokuskan hanya sampai pada langkah pengujian produk pada uji coba terbatas atau skala kecil atau tahap ke enam. Produk yang telah tersusun menjadi sebuah modul praktikum, kemudian dilakukan uji validasi oleh ahli media dan ahli materi. Hasil dari validasi tersebut dilakukan revisi dengan perbaikan sesuai dengan masukan validator lalu dilakukan uji coba dengan lapangan utama skala kecil dengan sampel 5 s.d. 10 mahasiswa. Hasil dari ujicoba ini akan dilakukan analisis dan perbaikan sehingga produk menjadi media yang layak untuk rujukan dan petunjuk praktikum komputasi fisika.

Dalam menganalisis data hasil penelitian berupa tanggapan ahli materi dan media beserta hasil ujicoba berupa komentar dan saran perbaikan yang diuraikan secara deskriptif. Untuk menentukan kriteria kelayakan produk diperoleh dari lembar observasi berupa check list dengan kriteria penilaian 1-4 yang kemudian dikonversi menjadi data kuantitatif. Skor hasil validasi berupa data kuantitatif akan dianalisis untuk memperoleh skor ratarata yang menggunkan rumus:

$$
\bar{x}_{i}=\frac{\sum x}{N}
$$


dengan $\bar{x}_{i}$ merupakan skor rata-rata, $\sum x$ adalah jumlah skor, dan $N$ adalah jumlah responden.

\section{Hasil Penelitian dan Pembahasan}

Pengembangan produk dalam penelitian ini mengacu pada $R$ and $D$ model Borg and Gall yang terdiri dari sepuluh tahapan, namun penelitian ini tahapan pengambangan dilakukan sampai dengan tahap keenam yaitu tahap uji coba lapangan utama, yang merupakan uji coba pada skala kecil atau sampel terbatas. validasi ahli. Berikut penjelasan tahapan pengembangan:

\section{Analisis kebutuhan}

Mata kuliah Praktikum Komputasi Fisika di Program Studi Pendidikan Fisika, FKIP, Universitas Ahmad Dahlan dilaksanakan pada semester 5 (lima) dan merupakan mata kuliah wajib. Mahasiswa yang menempuh mata kuliah Komputasi Fisika (2 SKS) diwajibkan pula menempuh praktikumnya (1 SKS). Perkuliahan teori dilakukan di kelas, sedangkan praktikum di Laboratorium Teknologi Pembelajaran Sains (LTPS).

Selama ini praktikum dilaksanakan dengan mempraktikan apa yang diperoleh di perkuliahan teori.
Mahasiswa mencoba teori yang telah diperoleh di kelas untuk dipraktikumkan di laboratorium dengan pendampingan dari asisten praktikum. Tidak ada acuan yang pasti, hanya menggunakan buku-buku yang umumnya ditulis untuk mahasiswa fisika dan teknik, tidak ada pula modul praktikum yang jelas. Hanya berbekal pada catatan dari perkuliahan teori saja. Buku acuan yang digunakan, pembahasannya terlalu rumit dan mendalam, seringkali malah justru membingungkan mahasiswa. Dari segi capaian pembelajaran pun belum jelas. Justru seolah terlihat mahasiswa harus menguasai seluruh teknik komputasi numerik yang ada, yang tidak sesuai dengan capaian pembelajaran yang telah disepakati oleh asosiasi profesi. Modul yang dikembangkan tidak hanya sekedar modul, namun modul yang telah disesuaikan dengan capaian pembeajaran yang telah disepakati.

\section{Perancangan produk}

Dalam Rencana Pembelajaran Semester (RPS) mata kuliah Praktikum Komputasi Fisika tertuliskan mengenai capaian pembelajaran umum dan khusus dalam mata kuliah ini, yang kurang lebih tertampil pada tabel 2 berikut.

Tabel 2 Ringkasan RPS Mata Kuliah

\begin{tabular}{|c|c|c|c|}
\hline \multirow{2}{*}{\multicolumn{2}{|c|}{$\begin{array}{l}\text { Mata Kuliah } \\
\text { Kode Mata Kuliah }\end{array}$}} & : & Praktikum Komputasi Fisika \\
\hline & & : & 0755711 \\
\hline \multirow{3}{*}{$\begin{array}{l}\text { Capaian } \\
\text { Pembelajaran }\end{array}$} & Keterampilan & : & Mampu menerapkan pemikiran logis, kritis, sistematis, dan \\
\hline & Umum & & $\begin{array}{l}\text { inovatif dalam konteks pengembangan atau implementasi ilmu } \\
\text { pengetahuan dan teknologi yang memperhatikan dan menerapkan } \\
\text { nilai humaniora yang sesuai dengan bidang pendidikan fisika }\end{array}$ \\
\hline & $\begin{array}{l}\text { Keterampilan } \\
\text { Khusus }\end{array}$ & : & $\begin{array}{l}\text { Menguasai matematika, komputasi, dan instrumentasi untuk } \\
\text { mendukung pemahaman konsep fisika }\end{array}$ \\
\hline \multirow{3}{*}{\multicolumn{2}{|c|}{ Tujuan Pembelajaran }} & : & $\begin{array}{l}\text { 1. Mahasiswa mampu menguasai teknik komputasi untuk } \\
\text { menyelesaikan permasalahan fisika }\end{array}$ \\
\hline & & & $\begin{array}{l}\text { 2. Mahasiswa mampu memahami metode numerik penyelesaian } \\
\text { persoalan fisika yang rumit }\end{array}$ \\
\hline & & & $\begin{array}{l}\text { 3. Mahasiswa mampu membuat algoritma untuk penyelesaian } \\
\text { persoalan fisika }\end{array}$ \\
\hline \multicolumn{2}{|c|}{ Konten minimal MK } & : & $\begin{array}{l}\text { Metode numerik untuk menyelesaikan akar persamaan polinomial, } \\
\text { persamaan linier, dan persamaan diferensial }\end{array}$ \\
\hline
\end{tabular}

Dari RPS sudah jelas dituliskan bahwa tidak semua metode numerik harus dikuasai oleh mahasiswa jurusan Pendidikan Fisika. Hanya beberapa metode saja naum mendalam. RPS di atas sudah disesuakan dengan hasil rumusan dari PSI, sehingga diperlukan perangkat pendukung untuk memperoleh capaian pembelajaran yang diinginkan.

Modul pada penelitian ini dirancang membunyai delapan bab, dengan satu bab pendahuluan, enam bab materi pembelajaran, dan satu bab terakhir merupakan materi pengayaan. Modul yang ditulis menggunakan Matlab sebagai bahasa pemrogramnya. Pada setiap bab disertai dengan latihan pembuatan program penggunakan Matlab. Gambar 1 merupakan cover dari modul yang telah dihasilkan. 


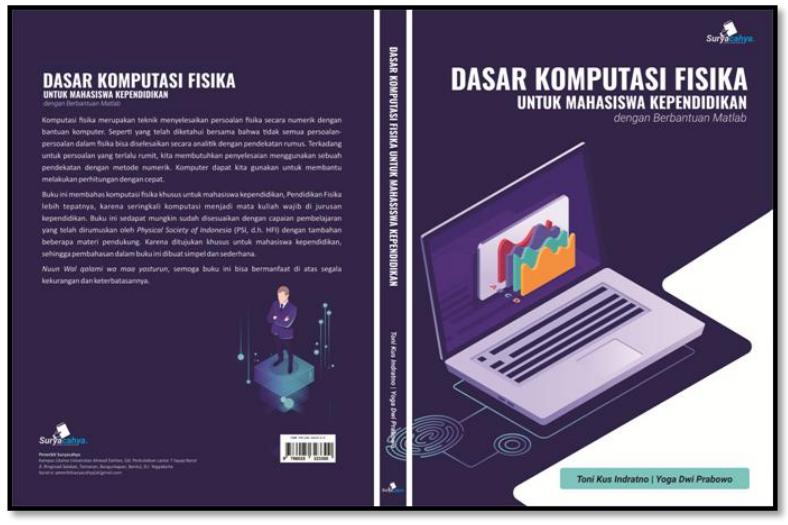

Gambar 1 cover modul komputasi fisika

Pada bagian awal modul, yaitu pada bagian pendahuluan disinggung pula tentang kaitan antara ilmu dan agama. Hal ini sebagai penegasan bahwa ilmu pengetahuan tidak bisa terpisahkan dengan agama. Gambar 2 menampilkan sedikit pembahasan yang menyinggung tentang agama tersebut.

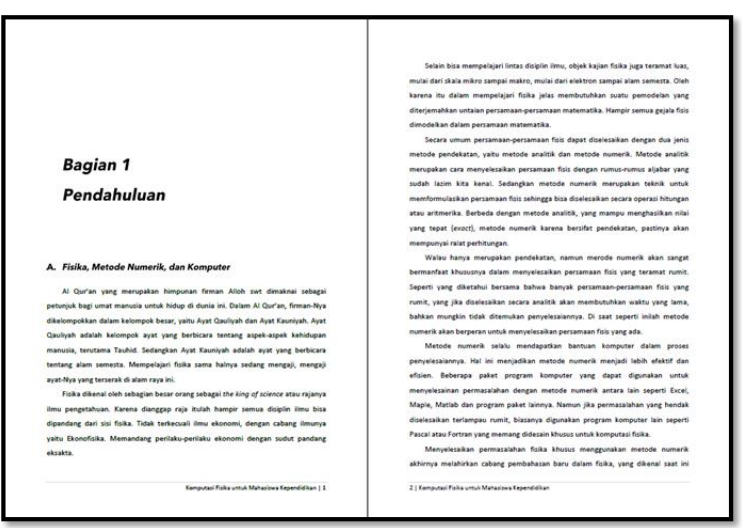

Gambar 2 isi buku bagian pendahuluan

Seperti yang telah diungkapkan sebelumnya bahwa setiap akhir pembahasan pada bab buku ini, diberikan latihan pemrogramannya menggunakan software Matlab. Hal ini bertujuan agar mahasiswa terbiasa menggunakan teknologi dalam melakukan analisis numerik, karena akan membutuhkan waktu yang lama jika analisis numerik dihitung dengan cara manual. Gambar 3 menampilkan contoh latihan pemrogramann di setiap akhir bab.

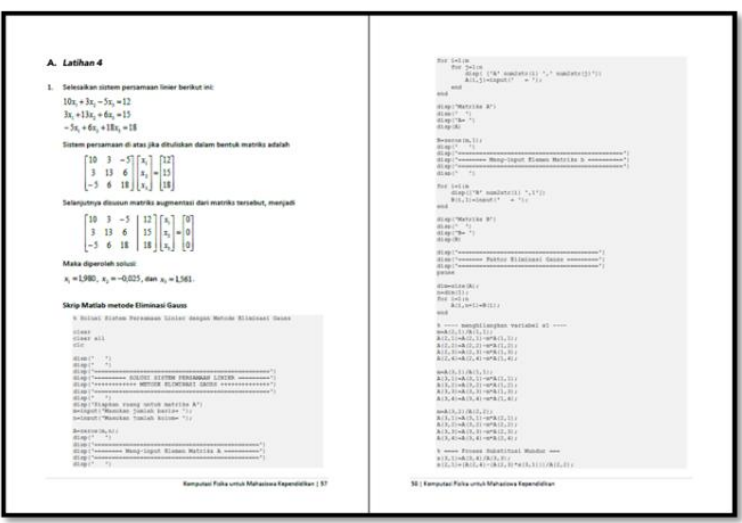

\section{Gambar 3 contoh tampilan latihan}

Pada bab akhir modul ini disampaikan materi pengayaan berupa pembahasan tentang Graphic User Interface (GUI) Matlab untuk semakin menambah khazanah keilmuan mahasiswa tentang penggunaan Matlab dalam komputasi fisika. GUI merupakan fasilitas untuk memudahkan pengguna atau end-user mengoperasikan program yang telah dibuat. Jika tidak menggunakan GUI, maka pengguna harus bekerja melalui interface command line yang tentu saja lebih sulit. Dengan GUI kita juga bisa mengekspor program dalam bentuk .exe, sehingga end-user tidak memerlukan instalasi Matlab secara full. Gambar 4. menunjukkan contoh pembahasan tentang GUI Matlab.

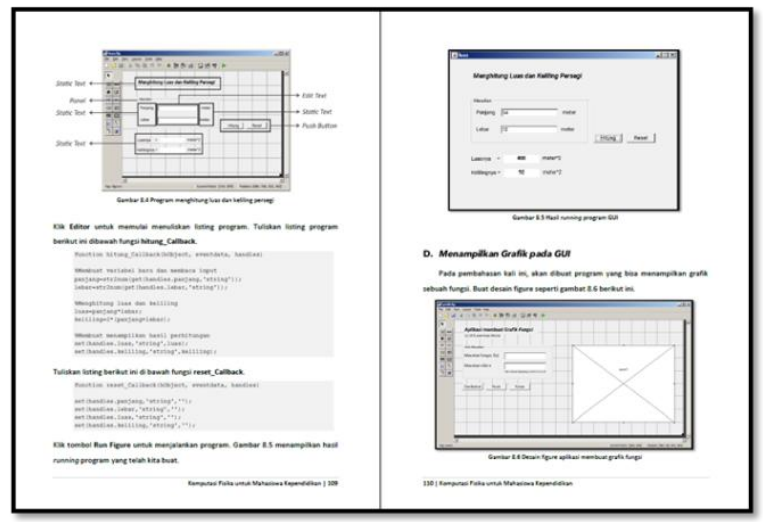

Gambar 4 contoh tampilan pembahasan GUI Matlab

\section{Validasi ahli}

Modul praktikum yang telah dikembangkan dilakukan uji kelayakan oleh para ahli materi dan media pembelajaran. Untuk uji validasi dari ahli materi komputasi fisika dilakukan oleh Bapak Dr. Moh. Toifur, yang memiliki kompetensi dalam bidang fisika dan komputasi. Sedangkan uji validasi media pembelajaran dilakukan oleh Avanti Vera Risty P., M.Pd. yang memiliki kompetensi dalam bidang teknologi pembelajaran. Penilaian dari ahli materi diperoleh nilai rata-rata sebesar 85,00 dengan kriteria baik. Sedangkan hasil penilaian dari ahli media pembelajaran diperoleh hasil skor sebesar 92,85 dengan kriteria sangat baik. Kesimpulan dari para ahli menyatakan bahwa modul ini sangat layak untuk digunakan sebagai bahan pembelajaran dalam praktikum komputasi fisika di jurusan kependidikan. Secara umum masukan dari ahli media terkait ukuran gambar dalam pembahasan yang kurang diperbesar. Selain itu, pada cover modul juga perlu ditampilkan konsep fisika agar lebih menarik lagi.

Hasil dari validasi ahli dijadikan sebagai referensi bagi peneliti untuk menyempurnakan produk yang dikembangkan. Selanjutnya pada tahap berikutnya akan dilakukan uji coba lapangan utama, yang merupakan uji coba skala kecil pada para pengguna (mahasiswa) untuk memperoleh respon pengguna terhadap produk yang telah dikembangkan. 


\section{Uji coba lapangan utama}

Hasil penilaian dari ahli materi dan media dijadikan sebagai dasar perbaikan produk agar sesuai dengan kelayakan sebuah bahan pembelajaran. Selanjutnya setelah dilakukan perbaikan sesuai dengan masukan dan penilaian dari ahli, produk diujicobakan ke beberapa sampel mahasiswa untuk melihat respon mahasiswa terhadap produk yang telah dikembangkan. Sampel mahasiswa yang digunakan adalah mahasiswa semester 5 dan semester 7 di Prodi Pendidikan Fisika UAD sebanyak sepuluh mahasiswa. Pengambilan sampel ini didasarkan pada asumsi bahwa mahasiswa di semester 5 dan 7 sudah pernah menempuh praktikum komputasi fisika tanpa menggunakan modul. Sehingga dengan ini diharapkan bisa melihat respon perbedaan antara praktikum dengan modul dan tanpa modul.

Instrumen respon pengguna menggunakan USE Questionnaire: Usefulness, Satisfaction, and Ease of use (Lund, 2001) yang diterjemahkan menjadi beberapa butirbutir pertanyaan. Tabel 3 berikut ini merupakan hasil penilaian respon pengguna terhadap produk yang telah dikembangkan.

Tabel 2 Respon Penggunan terhadap modul praktikum komputasi fisika

\begin{tabular}{|c|c|c|c|}
\hline No. & Aspek & Skor & $\begin{array}{c}\text { Prosentase } \\
(\%)\end{array}$ \\
\hline 1 & Kegunaan (Usefulness) & 28,7 & 89,69 \\
\hline 2 & $\begin{array}{l}\text { Kemudahan Penggunaan } \\
\text { (Ease to Use) }\end{array}$ & 22,4 & 93,33 \\
\hline 3 & $\begin{array}{l}\text { Kemudahan untuk Belajar } \\
\text { (Ease to Learning) }\end{array}$ & 14,2 & 88,75 \\
\hline 4 & $\begin{array}{l}\text { Kepuasan dalam penggunaan } \\
\text { (Satisfaction) }\end{array}$ & 22,3 & 92,92 \\
\hline \multicolumn{3}{|c|}{ Rata-rata } & 91,17 \\
\hline
\end{tabular}

Berdasarkan hasil ujicoba lapangan utama diperoleh hasil bahwa prosentase respon pengguna mencapai 91,17\% yang merupakan kategori sangat baik. Apresiasi dari para pengguna terhadap modul yang telah dikembangkan bisa terlihat pada lembar kusioner yang telah mereka isi. Beberapa masukan dari pengguna akan dijadikan bahan masukkan untuk proses perbaikan yang akan datang sebelum diimplementasikan dalam proses pembelajaran di Praktikum Komputasi Fisika.

\section{Kesimpulan}

Modul praktikum dasar komputasi fisika untuk mahasiswa jurusan kependidikan telah dikembangkan, dan menyesuaikan dengan capaian pembelajaran yang telah ditetapkan oleh asosiasi. Modul ini juga telah dinilai kelayakannya oleh ahli materi kriteria penilaian Sangat Baik, dan ahli media dengan kreiteria Baik. Uji coba skala terbatas dilakukan untuk melihat respon pengguna terhadap modul yang dikembangkan. Pengguna mengkategorikan produk ini dalam kategori Sangat Baik dan layak untuk digunakan.

\section{Kepustakaan}

[1] Borg, W. \& Gall, M., 1989. Educational Research: An Introduction, Fifth Edition. New York: Longman.

[2] Fitri, U. R., Desnita \& Handoko, E., 2015. Pengembangan Modul Berbasis Discovery-Inquiry untuk Fisika SMA Kelas XII Semester 2. JPPPF - Jurnal Penelitian \& Pengembangan Pendidikan Fisika, 1(1), pp. 47-54.

[3] ITS, 2014. Pedoman Penyusunan Kurikulum 2014 -2019. Surabaya: Institut Teknologi Sepuluh Nopember.

[4] Majid, A., 2012. Perencanaan Pembelajaran Mengembangkan Standar Kompetnsi Guru. Bandung: Rosda Karya.

[5] Mulyono \& Asih, T. N., 2013. Pembelajaran NHT Pada Metode Numerik dengan Bantuan Aplikasi Maple. Unnes Journal of Mathematics Education Research, 2(1), pp. 190-196.

[6] Pendidikan Fisika, T. P. K., 2015. Buku Kurikulum Program Studi Pendidikan Fisika FKIP Universitas Ahmad Dahlan. Yogyakarta: program Studi Pendidikan Fisika FKIP UAD.

[7] Suparno, S., 2008. Staff Universitas Indonesia. [Online] Available at: http://staff.ui.ac.id/system/files/users/supriyanto.si/material/komp utasiedisi3.pdf [Diakses 9 Desember 2018].

[8] T. A. P. F., 2016. Rumusan Profil Lulusan dan Capaian Pembelajaran Asosiasi Program Studi Pendidikan Fisika. Surakarta: Muhammadiya.

[9] Wulandari, T. C., 2016. Pengembangan Modul Barisan dan Deret Berbasis Konstekstual. Jurnal Inspirasi Pendidikan Universitas Kanjuruhan Malang, pp. 883-889.

[10] Yanse, N. M. N., 2012. EFektivitas Metode Adams BashforthMoulton Order Sembilan Dalam Menganalisis Model Penyebaran Penyakit Demam Berdarah Dengue (DBD), Jember: FKIP Universitas Jember. 